\title{
Environmental Change Detection Study in the Wider Area of Lignite Mines
}

\author{
Ioannis Kotaridis*, Maria Lazaridou \\ Laboratory of Photogrammetry - Remote Sensing, School of Civil Engineering, Faculty of Engineering, \\ Aristotle University of Thessaloniki, 54124 Thessaloniki, Greece
}

Copyright $(2018$ by authors, all rights reserved. Authors agree that this article remains permanently open access under the terms of the Creative Commons Attribution License 4.0 International License

\begin{abstract}
Environmental monitoring of mine areas offers critical information about how they affect both natural and man-made environment. The Ptolemaida-Amyntaio lignite center plays a very important role in electrical industry of Greece, since it is the main energy fuel. The spatial growth of the lignite mine causes land cover change in the wider area. This paper aims to detect land cover changes in the wider area of the mines, in northwestern Greece, between two time periods using Remote Sensing and Geoinformation system (RS and GIS) methods. For this purpose multispectral images for both times were acquired, from Landsat data and a supervised classification was applied. Finally, qualitative and quantitative results obtained through visual interpretation and digital change detection study indicate that there has been a great increase in mine areas, affecting both agricultural land and man-made environment.
\end{abstract}

Keywords Digital Change Detection, Land Cover, Lignite Mines, Multispectral Imagery, Remote Sensing

\section{Introduction}

The applicability of Remote Sensing methods in handling environmental issues has been proven and well established. Integration with Geographic Information Systems, which are computer tools that allow the processing of maps, geographically referenced digital images and tabular information [1], offers a valuable tool in the wide context of environmental monitoring.

Understanding landscape form, changes and interaction between human activities and natural phenomena is a necessary step in rational land management and decision improvement [2].

Also, science of remote sensing offers the possibility of environmental monitoring in wide areas in a cost-effective way and provides important information [3]. There are quite a number of applications of Remote Sensing methods in change detection, which in particular include changes in land cover and land use, changes in vegetation, changes in wetlands, forest cover, urban changes, crop monitoring, as well as environmental changes [4].

There are many methods that are implemented and have been developed through the passage of decades of satellite remote sensing technique. However, authors agree that there is not a universal change detection method and it is up to the final user to choose the most appropriate approach [5].

This paper presents an effort to detect environmental changes in the wider area of Public Power Corporation (DEI) lignite mines using two multispectral images from the years 1987 and 2016, that are available free of cost and come from the archive of Landsat satellite missions. The process was based on the method of land cover change detection with post - classification comparison. It requires the comparison of two independently classified imageries and it has been proven that it is an effective method, due to the fact that the data from two different acquisition dates are classified individually and in this way the possible problems due to the atmospheric differences and those related to the sensor between the two dates are minimized [6]. The accuracy of the aforementioned method depends on the accuracy of the initial classifications [7].

It is pointed out that Corine Land Cover (CLC) change layers were not used for land cover change detection in the study area, owing to the fact that CLC is produced by the majority of countries with visual interpretation of satellite imageries [8].

\section{Study Area}

The study area that was chosen for the land cover change detection is located in the northwest part of mainland Greece, as it appears in Figure 1 as shown below and includes a part of the regional unit of Kozani plus a smaller part of the regional units of Florina and Imathia. 


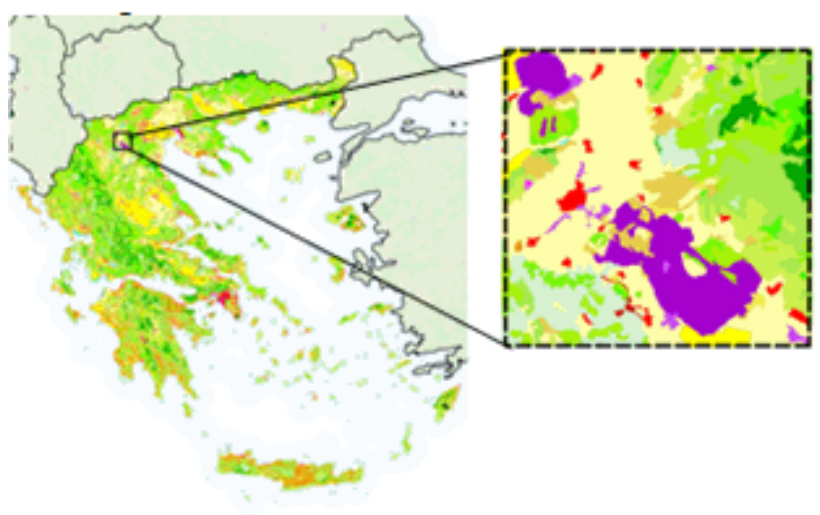

Figure 1. Study area in CORINE Land Cover base map (Sources: Copernicus (2017), Eurostat, modified by the author).

The selection of the study area was based on the intense environmental interest that it presents. During the reference time period, extensive mining activity is observed for producing electrical energy followed by relocation of settlements that forms an anthropogenic intervention. This intervention combined with natural factors changes land cover and creates a dynamic environment. Therefore, the environmental monitoring of this area becomes essential.

\section{Materials and Methods}

The diagram that is presented below includes the basic phases of the procedure that implemented so as to detect the land cover changes in the study area.

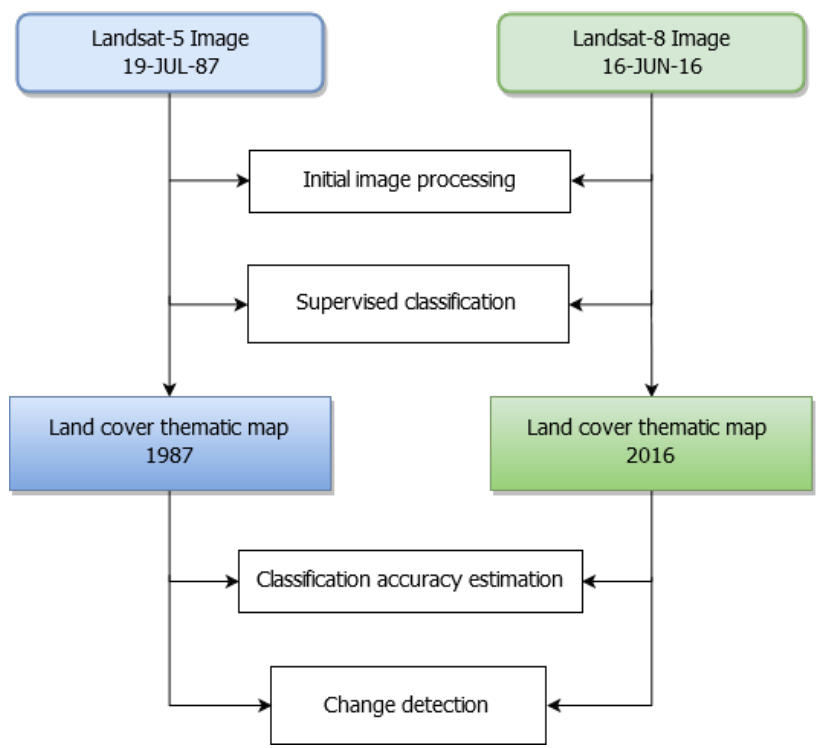

Figure 2. Flowchart with the basic phases of the procedure implemented for land cover change detection.
The satellite multispectral imageries were downloaded from https://earthexplorer.usgs.gov, as they became freely available online, since October 2008.

In this paper, it was considered appropriate to use collection 1 Surface Reflectance Level-2 products from Landsat archive. The atmospheric correction aims to achieve a sharper view of land's surface, as though the atmosphere was not between the satellite and the ground [9]. The criteria for the selection of scenes were limited cloud coverage, high quality and close acquisition dates. Cloud cover was set below $10 \%$, collection category as Tier 1 (T1) and data type as L1TP.

Additionally, in order to represent the relief of the study area, ASTER Global DEM image with 1 arc-second pixel size (about $30 \mathrm{~m}$ at the equator) was used [10]. Geographic coordinates of the southwest corner of the image are $21^{\circ} \mathrm{E}, 40^{\circ} \mathrm{N}$.
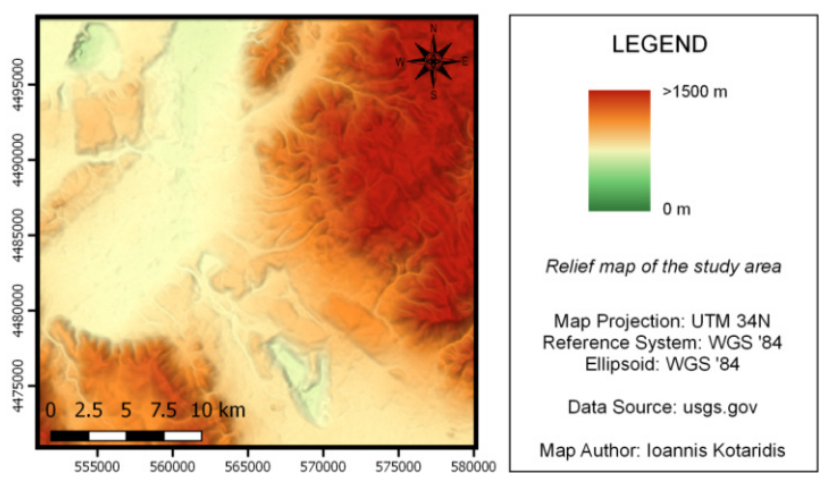

Figure 3. Relief map of the study area

Band set used were Blue, Green, Red, Near Infrared (NIR) Shortwave Infrared (SWIR) 1 and Shortwave Infrared (SWIR) 2, which are single band raster data with spatial resolution of $30 \mathrm{~m}$, were used.

Digital processing of the images was implemented in QGIS 2.18 software and the Semi-Automatic Classification Plugin (SCP) was used for the supervised classification of multispectral imageries.

In order to clip Landsat scenes at the boundaries of the study area, a vector layer was created, while for the definition of Band set, the spectral bands were chosen and a unique raster that stack all the bands was created.

Furthermore, a few color composites were created in order to facilitate the selection of the training areas that are required in order to train the classifier. In Figure 4, RGB 3-2-1 composite of Landsat 5 image (1987) and RGB 4-3-2 composite of Landsat 8 image (2016) are displayed, depicting the study area with natural colors. The difference in color composites combinations is due to the fact that Landsat 8 data include additional bands [11]. 

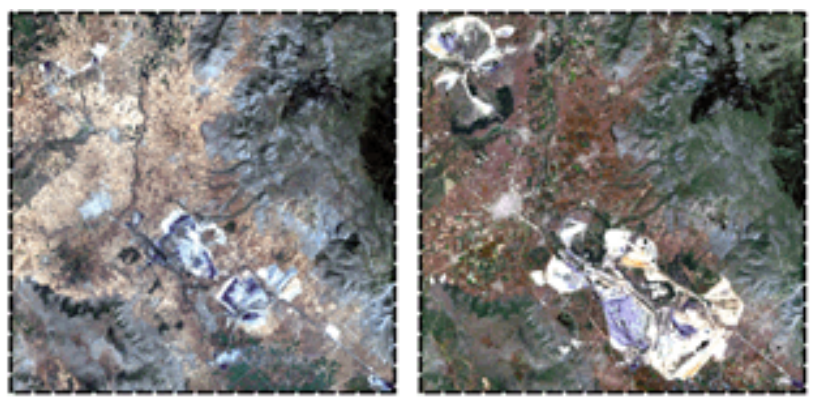

Figure 4. RGB 3-2-1 composite of Landsat 5 image (1987) (left) and RGB 4-3-2 composite of Landsat 8 image (2016) (right).

For the classification of multispectral images in this paper, supervised classification was implemented and maximum likelihood algorithm was applied.

Supervised classification is the method that is mostly used for the quantitative analysis of remote sensing imagery [12].

The purpose of the classification is to determine in each of the images of the study area the land cover class for the whole of the pixels. The selection of the land cover classes was done a priori and are:

1) Water body

2) Forest area

3) Barren land

4) Built-up area

5) Agricultural land

6) Mine area

The selection of training areas for each land cover class was based on personal knowledge of the study area. A typical example of land cover class Mine area is presented in Figure 5 that follows.

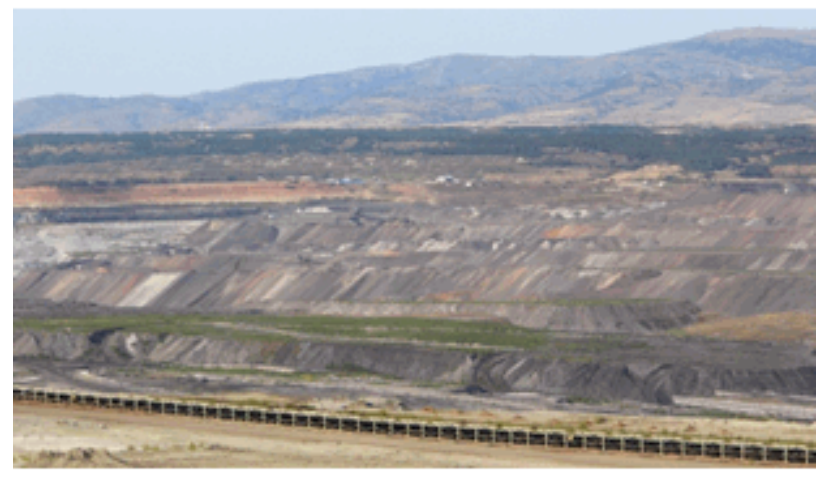

Figure 5. Viewpoint of DEI lignite mines (acquisition date: 21/8/2017)

Moreover, in order to facilitate further the selection of training areas, it was considered useful to apply the pan-sharpening technique to Landsat 8 image. In particular, this technique is applied in order to combine the improved spatial information of the panchromatic band (PAN band), which is $15 \mathrm{~m}$, with the spectral information of the multispectral bands. In SCP plugin, Brovey Transform method is included, that preserves the spatial information but distorts the multispectral information to a certain extent. It is a fast and efficient pansharpening method that has been widely used in remote sensing studies [13]. It can be calculated using a simple mathematical formula. However, it is quite appropriate for the better selection of training areas in Landsat 8 image. The outcome of Pansharpening is a multispectral image with $15 \mathrm{~m}$ spatial resolution.
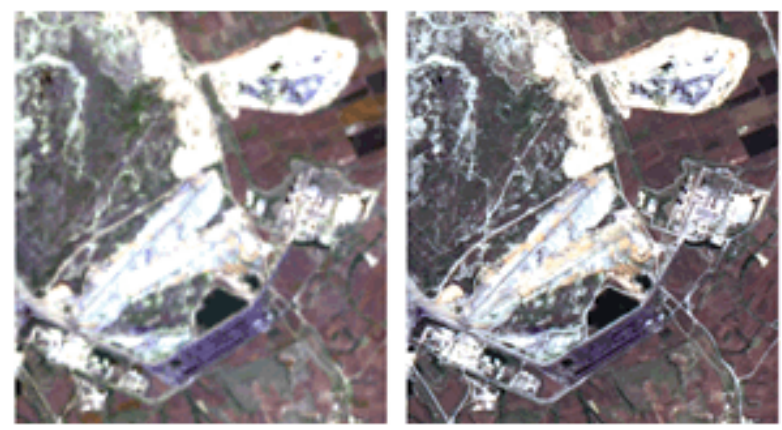

Figure 6. Viewpoint of study area showing a part of Amyntaio mine, before (left) and after (right) the application of pan-sharpening.

\section{Results}

After the selection of training areas in each image, their spectral signatures were assessed for possible overlaps. This is a time-consuming procedure, especially in a wide study area, having a quite heterogeneous terrain and diverse relief. Each pixel is classified in the class with the highest probability [14] and the classified images were produced.

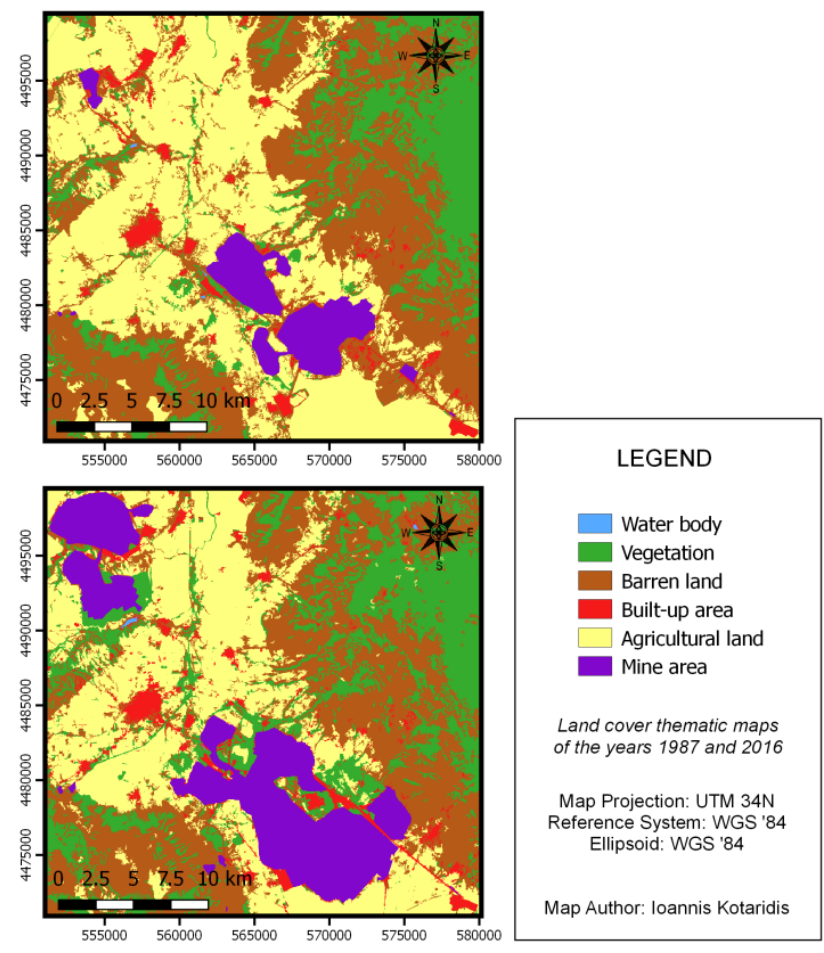

Figure 7. Landsat 5 classified image of the year 1987 (above) and Landsat 8 classified image of the year 2016 (below). 
Landsat 5 classified image (1987) and Landsat 8 classified image (2016) based on the land cover classes that have been mentioned before, are presented in the form of a land cover thematic map.

Next, it was considered useful to create and superimpose the elevation contour map of the study area over the layer of the classified image of the year 2016 . The result can be seen below in Figure 8 .

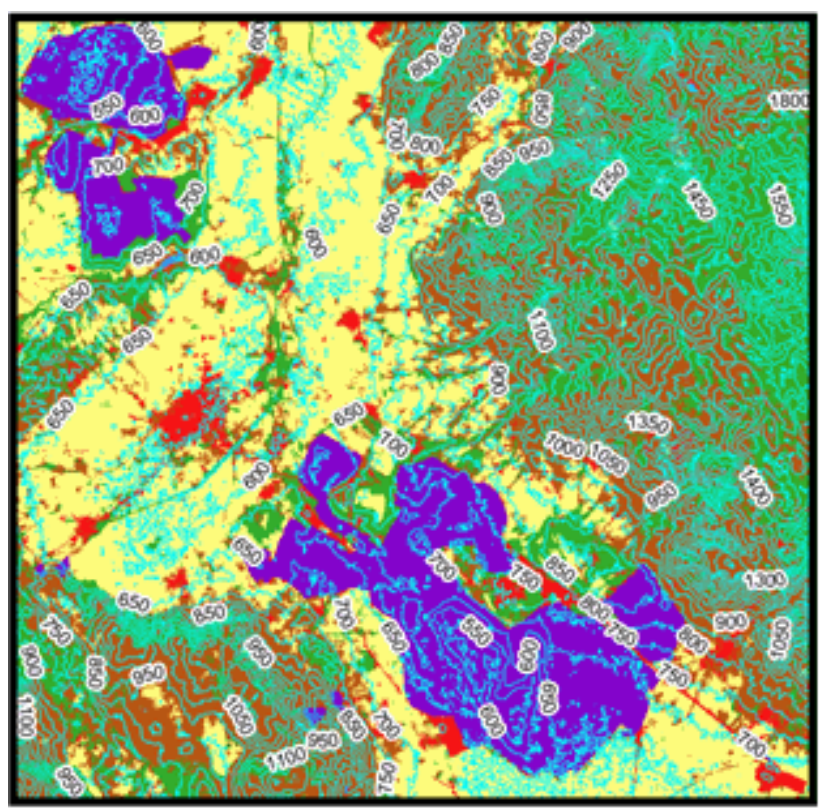

Figure 8. Elevation contour map overlayed with the classified image of the year 2016

The combination of relief information alongside the classified image helps to form a more complete opinion about the land covers of the study area. Additionally, it is in some measure a verification of the quality of the classification product.

After the classification process is completed, an evaluation of classification accuracy should be implemented, in order to ensure the validity of results, their evaluation and conclusions. The evaluation of accuracy, in the software that was used, is performed with the calculation of an error matrix, that compares the information from the classified image with reference data, which might come from an autopsy (ground truth data) for a number of areas [15]. In this paper, classification accuracy was calculated $88.43 \%$ for the classified image of the year 1987 and $88.90 \%$ for the classified image of the year 2016.

For the land cover change detection in the study area, as it has been mentioned before, the post-classification comparison method was chosen, for the years 1987 and 2016. After the production of the final classifications, a visual interpretation of the land cover maps was carried out and quantitative results were exported, regarding classification and land cover changes.

Visual interpretation and comparison of the classified images, lead to the following observations which are also environmental changes:

1) Increase of the area of the mines that take the place of crops and a certain amount of settlements.

2) Increase of vegetation in some parts of the study area.

Digital change detection with the post-classification comparison method offers the possibility to export quantitative results for the area of each land cover class. The results are presented in tables $1 \& 2$ along with the land cover change graph of the years 1987 and 2016 for each class.

Table 1. Quantitative results of Landsat 5 classified image.

\begin{tabular}{|c|c|c|c|}
\hline Class & Pixels sum & Percentage $(\%)$ & Area $\left(\mathrm{km}^{2}\right)$ \\
\hline Water body & 192 & 0.02 & 0.2 \\
\hline Vegetation & 146114 & 15.99 & 131.5 \\
\hline Barren land & 338719 & 37.06 & 304.8 \\
\hline Built-up area & 23276 & 2.55 & 20.9 \\
\hline Agricultural land & 355916 & 38.95 & 320.3 \\
\hline Mine area & 49670 & 5.44 & 44.7 \\
\hline
\end{tabular}

Table 2. Quantitative results of Landsat 8 classified image.

\begin{tabular}{|c|c|c|c|}
\hline Class & Pixels sum & Percentage (\%) & Area $\left(\mathrm{km}^{2}\right)$ \\
\hline Water body & 418 & 0.05 & 0.4 \\
\hline Vegetation & 195150 & 21.35 & 175.6 \\
\hline Barren land & 290580 & 31.80 & 261.5 \\
\hline Built-up area & 35657 & 3.90 & 32.1 \\
\hline Agricultural land & 268559 & 29.39 & 241.7 \\
\hline Mine area & 123523 & 13.52 & 111.2 \\
\hline
\end{tabular}

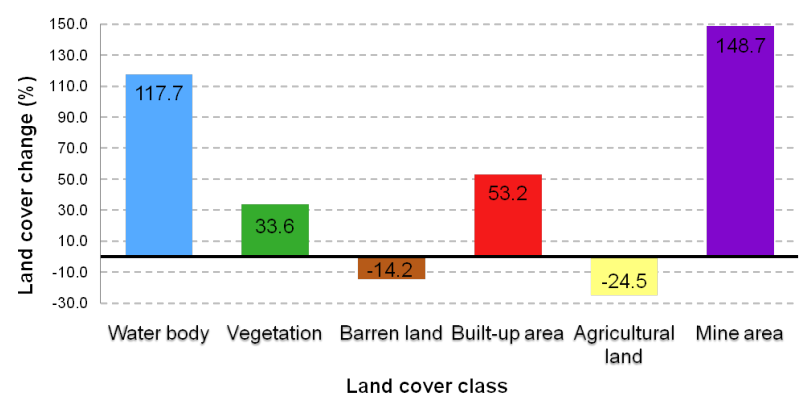

Figure 9. Land cover change for each land cover class of the years 1987 and 2016.

The quantitative presentation of results gives quantitative values to the observations from visual interpretation. The increase of the area of mines is estimated at $148.7 \%$, which is a noteworthy change. Moreover, $117.7 \%$ positive change noted in water bodies and $53.2 \%$ in built-up environment, that occupy however a small percentage of the study area and $33.6 \%$ in vegetation. Negative changes are observed in land cover classes of barren land and agricultural land with percentages of $-14.2 \%$ and $-24.5 \%$ respectively. 
However, the quantitative data of classified images and changes between the reference years form a preview of the changes in the study area. It is equally important to investigate individual changes per land cover class forming the overall picture of the changes. Specifically, it is important to find from which land cover class comes the additional area that is occupied by mines in 2016. The post-classification comparison method allows the export of such information that is from-to changes for each land cover class.

According to the data of the relevant table, it is noticed that the area occupied by mines in 2016 comes from cultivations $(54 \%)$, mines $(21 \%)$ and barren land $(18 \%)$ of the year 1987. Similarly, the area occupied by built-up environment comes from built-up areas (40\%), barren land $(26 \%)$ and cultivations (19\%) of the year 1987. The area occupied by water bodies comes from vegetated areas $(40 \%)$, barren land $(31 \%)$ and water bodies $(29 \%)$ of the year 1987. Lastly, the area occupied by vegetation mostly comes from vegetated areas (59\%) and barren land (25\%) of the year 1987.

Furthermore, it was considered useful to verify with an autopsy and ancillary data the most significant land cover changes, apart from the increase in mine areas. Specifically, the creation of an artificial lake in the north-east part of the study area with the construction of Mesovouno dam, is related to the substantial positive change in water bodies. The construction of new roads and artificial surfaces in mine areas is associated with the positive change in built-up areas. The vegetated areas that can be noticed close to lignite mines, come from the reclamation process.

Finally, the Settlements' distance from mine boundaries was calculated, for each of the years 1987 and 2016, in order to study the way it has changed. For the purpose of analyzing the spatial relationship between the weighted center of settlements and mine boundaries, a $2000 \mathrm{~m}$ buffer zone was created. The settlements that are located inside this zone were included in this nearest neighbor analysis. The results are presented in Figure 10.

Considering the results of the analysis, in $78.6 \%$ of the settlements the distance from mine boundaries was decreased. The most noteworthy negative changes observed in following settlements: Mavropigi $(-77.6 \%)$, Anargyroi (-67.3\%), Filotas (-67.3\%), Perdikkas (-63.7\%), Spilia (-46.4\%), Pontokomi (-43.9\%) and Pteleon (-41.5\%).
Moreover, the initial site of settlements that were covered by mines during the reference time period, is presented with blue tone. Additionally, it is intriguing that the landslide occurred in lignite mine of Amyntaio (north-west part of the study area) on 10 June 2017, is located close to Anargyroi settlement, that its distance from mines was significantly decreased. Accounting for the above mentioned factors, it is obvious that the mine extension in the study area affects the man-made environment.

\section{Conclusions}

When detecting land cover changes in an area of interest, the combination of Remote Sensing methods and Geographic Information System could be a considerable source of information and forms a powerful tool in decision making.

This paper describes a characteristic example of combining Remote Sensing methods with the tools Geographic Information System provides, as they integrate in QGIS software.

Regarding the change detection results in the study area, the changes that are observed through the process of visual comparison of the final products of classification involve the increase of the area of mines and vegetation in some areas.

The quantitative presentation of land cover changes showed positive increase of $148.7 \%$ in land cover class mine area. Moreover, the detailed presentation of from-to changes, showed that more than half of the area that is occupied by mines in 2016 comes from cultivations of 1987 and in smaller percentages by mines and barren land.

Land cover changes in the study area reveal a dynamically changing landscape, with many and important environmental changes during the reference time period. Land cover change detection, mainly as an outcome of anthropogenic intervention but also natural process, can offer reliable information about the nature of the changes and their effect on the greater area, contributing to monitoring environment's dynamics and for this reason it should be updated regularly. This type of information improves land management and being also an important tool in decision making in strategic level. 


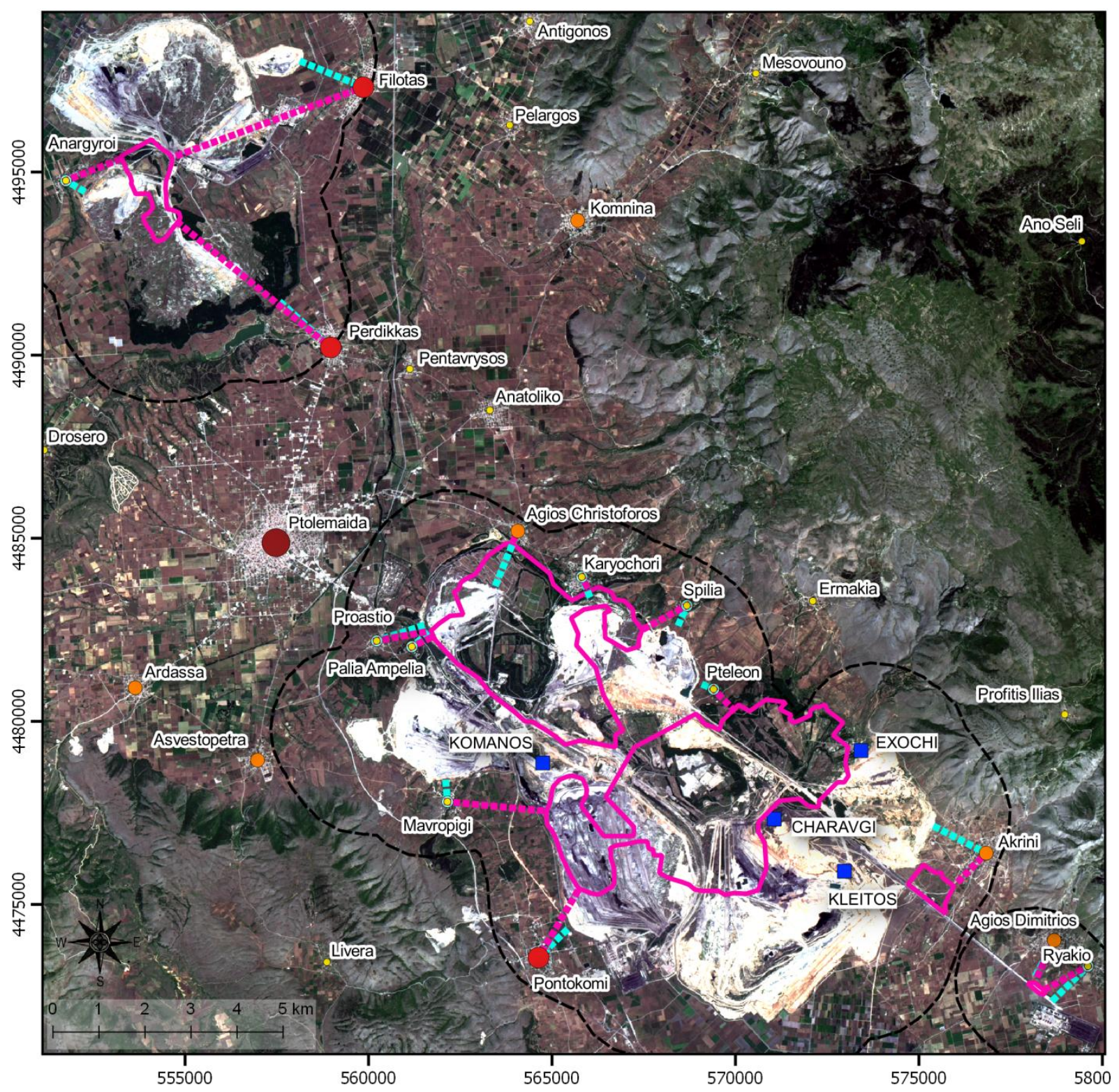

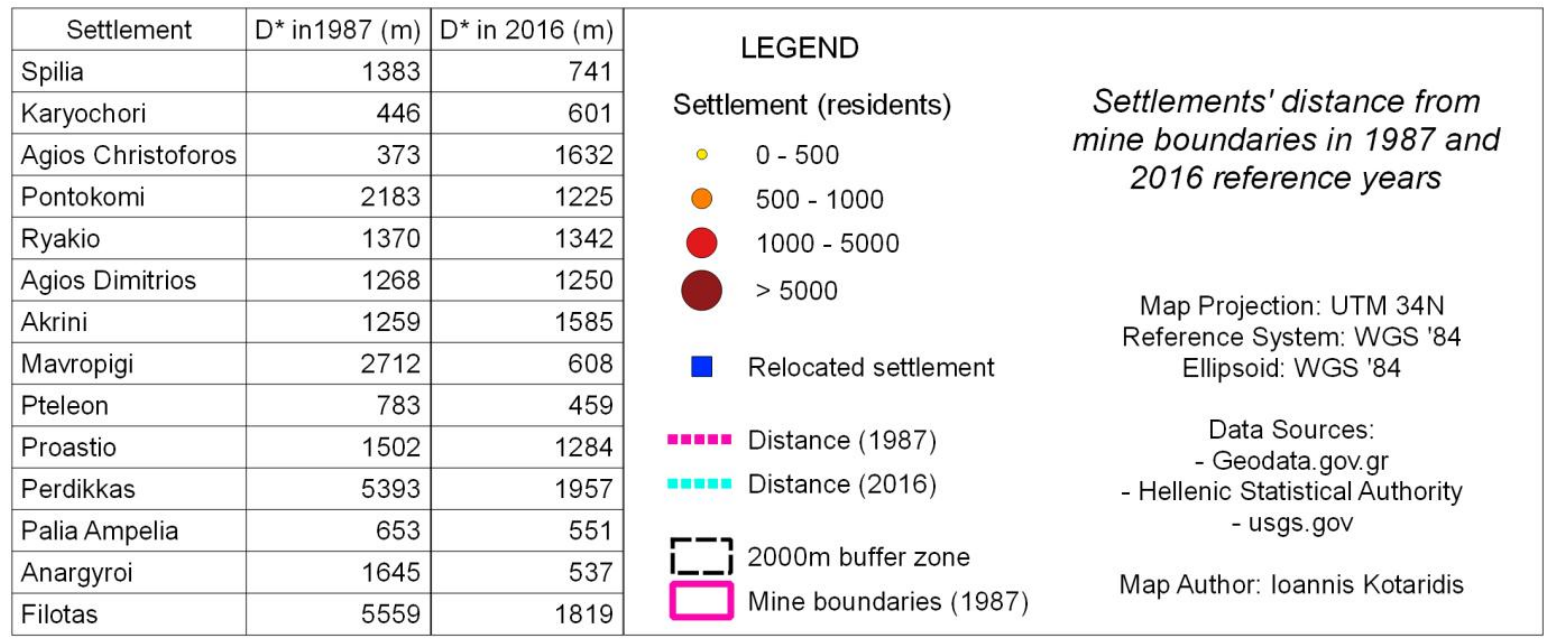

$* \mathrm{D}=$ Distance

Figure 10. Settlements' distance from mine boundaries in 1987 and 2016 reference years, with Landsat 8 pan-sharpened image (2016) in the background 


\section{REFERENCES}

[1] Bonham-Carter, G. F. (1994). Geographic Information Systems for Geoscientists: Modelling with GIS, Pergamon.

[2] Rawat, J. S. \& Kumar, M. (2015). Monitoring land use/cover change using remote sensing and GIS techniques: A case study of Hawalbagh block, district Almora, Uttarakhand, India, The Egyptian Journal of Remote Sensing and Space Science [online], 18 (1), 77-84, available from:

http://www.sciencedirect.com/science/article/pii/S1110982 315000034 [Date of access: 22 August 2017]

[3] Khatami, R., Mountrakis, G. \& Stehman, S. V. (2016). A meta-analysis of remote sensing research on supervised pixel-based land-cover image classification processes: General guidelines for practitioners and future research, Remote Sensing of Environment [online], 177, 89-100, available from:

http://www.sciencedirect.com/science/article/pii/S0034425 716300578 [Date of access: 22 August 2017]

[4] Lu, D., Mausel, P., Brondízio, E. \& Moran, E. (2004). Change detection techniques, International Journal of Remote Sensing [online], 25 (12), 2365-2401, available from:

http://www.tandfonline.com/doi/abs/10.1080/0143116031

000139863 [Date of access: 23 August 2017]

[5] Tewkesbury, A. P., Comber, A. J., Tate, N. J., Lamb, A. \& Fisher, P. F. (2015). A critical synthesis of remotely sensed optical image change detection techniques, Remote Sensing of Environment [online], 160, 1-14, available from: http://www.sciencedirect.com/science/article/pii/S0034425 715000152 [Date of access: 22 August 2017]

[6] Shalaby, A. \& Tateishi, R. (2007). Remote sensing and GIS for mapping and monitoring land cover and land-use changes in the Northwestern coastal zone of Egypt, Applied Geography [online], 27 (1), 28-41, available from: http://www.sciencedirect.com/science/article/pii/S0143622 806000154 [Date of access: 22 August 2017]

[7] Mei, A., Manzo, C., Fontinovo, G., Bassani, C., Allegrini, A. \& Petracchini, F. (2016). Assessment of land cover changes in Lampedusa Island (Italy) using Landsat TM and OLI data, Journal of African Earth Sciences [online], 122,
15-24, available from:

http://www.sciencedirect.com/science/article/pii/S1464343 X15001247 [Date of access: 21 August 2017]

[8] Copernicus (2017). CORINE Land Cover [online], available from: http://land.copernicus.eu/pan-european/corine-land-cover [Date of access: 17 August 2017]

[9] NASA (2017). Now \& Then : The History of Portrait U.S.A [online], available from:

https://landsat.gsfc.nasa.gov/now-then-landsat-u-s-mosaics / [Date of access: 3 August 2017]

[10] USGS (2014). Routine ASTER Global Digital Elevation Model [online], available from:

https://lpdaac.usgs.gov/dataset_discovery/aster/aster_produ cts_table/astgtm [Date of access: 10 August 2017]

[11] USGS (2017). How do Landsat 8 band combinations differ from Landsat 7 or Landsat 5 satellite data? [online], available from:

https://landsat.usgs.gov/how-do-landsat-8-band-combinati ons-differ-landsat-7-or-landsat-5-satellite-data [Date of access: 4 August 2017]

[12] Richards, J. A. (2013). Remote sensing digital image analysis: An Introduction, 5th ed. [online], Springer, Berlin, available from:

link.springer.com/content/pdf/10.1007/978-3-642-30062-2 .pdf [Date of access: 10 September 2017]

[13] Johnson, B. A., Tateishi, R. \& Hoan, N. T. (2012). Satellite Image Pansharpening Using a Hybrid Approach for Object-Based Image Analysis, ISPRS International Journal of Geo-Information [online], 1 (3), 228-241, available from: http://www.mdpi.com/2220-9964/1/3/228 [Date of access: 5 August 2017]

[14] Rujoiu-Mare, M. R. \& Mihai, B. A. (2016). Mapping Land Cover Using Remote Sensing Data and GIS Techniques: A Case Study of Prahova Subcarpathians, Procedia Environmental Sciences [online], 32, 244-255, available from:

http://www.sciencedirect.com/science/article/pii/S1878029 616001626 [Date of access: 22 August 2017]

[15] Congedo, L. (2016). Semi-Automatic Classification Plugin Documentation [online], available from: http://dx.doi.org/10.13140/RG.2.2.29474.02242/1 [Date of access: 20 September 2017] 